\title{
The Impact of Workplace Ostracism on Stress and Employee Engagement
}

\author{
Asif Hussain SAMO iD a Shakir KHAN ${ }^{\text {iD }}$ bouma ALi iD c Sarfaraz ALi id d \\ a Lecturer in Department of Business Administration at Sindh Madressatul Islam University. asif.samo@smiu.edu.pk \\ bStudent in Department of Business Administration at Sindh Madressatul Islam University. shakir1529@gmail.com \\ cStudent in Department of Business Administration at Sindh Madressatul Islam University. noumanali1996@gmail.com \\ d Student in Department of Business Administration at Sindh Madressatul Islam University. sarfarazawan555@gmail.com
}

\begin{tabular}{|c|c|}
\hline ARTICLE INFO & ABSTRACT \\
\hline $\begin{array}{l}\text { Keywords: } \\
\text { Workplace Ostracism } \\
\text { Stress }\end{array}$ & $\begin{array}{l}\text { Purpose - This research aims to find out the impact of workplace ostracism on stress and } \\
\text { employee engagement; this study is beneficial for organizations specific to Banking Sectors so that } \\
\text { they can manage their employees correctly. }\end{array}$ \\
\hline $\begin{array}{l}\text { Employee Engagement } \\
\text { Performance } \\
\text { Organization }\end{array}$ & $\begin{array}{l}\text { Design/methodology/approach - Quantitative research method was used in this research } \\
\text { followed with non-probability convenient sampling with the sample size of } 330 \text { of employees } \\
\text { working in the banking sectors located in Karachi both Public \& Private, the instruments for } \\
\text { measuring continuous variable are adopted from previous research. }\end{array}$ \\
\hline $\begin{array}{l}\text { Received } 27 \text { August } 2019 \\
\text { Revised } 10 \text { December } 2019 \\
\text { Accepted } 26 \text { December } 2019\end{array}$ & $\begin{array}{l}\text { Findings - We have found by testing our hypotheses that there is a significant positive impact of } \\
\text { Ostracism on Stress, on the other hand, it has been found that there is a negative impact of } \\
\text { Ostracism on Employee Engagement. }\end{array}$ \\
\hline $\begin{array}{l}\text { Article Classification: } \\
\text { Research Article }\end{array}$ & $\begin{array}{l}\text { Discussion - The theoretical implication of the research is that our results reinforced the past } \\
\text { theories and the practical implication that ostracism decreases the productivity of employees, for } \\
\text { increasing the productivity of employees, the organization should decrease the level of ostracism } \\
\text { at the workplace, and it will be beneficial for the banking sector. }\end{array}$ \\
\hline
\end{tabular}

\section{Introduction}

\subsection{Preamble}

The word workplace ostracism means when the employees feel that they are ignored by the employees who are working with them at the workplace (Ferris, Brown, Berry, \& Lian, 2008). In organizations where there is workplace ostracism, it causes a higher level of depression and lower level of satisfaction to organization's employees (Hitlan, Cliffton, \& Desoto, 2014; Ferris, 2008). One survey of 262 people, conducted on workplace ostracism, states that $64 \%$ employees ignored their colleagues at the workplace, and $29 \%$ employees intentionally left the areas where they do not want to spend their time with colleagues (Fox, \& Stallworth, 2005). Two types of ostracism happen at the workplace, one is purposeful ostracism and second is unpurposeful ostracism. The former means, a person ignored someone intentionally and the person is aware of behavior, that person is doing this to hurt or target someone and mostly purposeful ostracism at the workplace is a silent treatment (Williams, Bernieri, \& Faulkner, 2003). The non-purposeful ostracism is when people are not ignoring others intentionally. They are unaware that their behavior is hurting someone (Sommer, Williams, Ciarocco, \& Baumeister, 2010). Workplace ostracism reduces the social interaction between colleagues, which affects employees' psychological and mental health, because when employees share their feelings and emotions, they feel mentally and psychologically relaxed (Heaphy, \& Dutton, 2008). One research shows that because of workplace ostracism, employees become stressful which results in turnover and reduction in desirable productivity of employees (Grandey, \& Cropanzano, 2000). This all hampers the job satisfaction and commitment of the employees (Authors, 2015). Moreover, it also increases the level of furious aggression, conflicts and counterproductive behavior. In this study, it has been attempted to explain the impact of workplace ostracism on employee engagement (Zhao, Peng, \& Sheard, 2013). A researcher argued that workplace ostracism has direct relationship with the physiological distress and stress will impact negatively on employee performance and engagement (Borman, \& Motowidlo, 2009)

\section{Önerilen Atıf/Suggested Citation}

Samo., A., H., Khan, S., Ali, N., Ali, S. (2019) The Impact of Workplace Ostracism on Stress and Employee Engagement, Journal of Business Research-Turk, 11 (4), 3471-3484. 


\section{A. H. Samo - S. Khan - N. Ali - S. Ali 11/4 (2019) 3471-3484}

ostracism also leads the various negative consequences because of its lead the social pain and stress (Ferris, 2008). Therefore, this study, in given context, have tried to explain the relationship of workplace ostracism with stress. Stress will negatively affect the productivity of employees; it also decreases the quality of work and the effectiveness of an individual (Savery, Luks, Savery, \& Luks, 2011). A person with high level of stress will find a decrease in the energy needed to perform tasks. Stress also makes unfavorable condition for an employee (Cohen, 1980). In the condition of stress, employees will likely underperform job tasks, they also have low tolerance level in stress and they are not able to avoid the distraction while doing work (Motowidlo, 1986). When employees feel ostracized by organization in important conversations, meetings, social activities or any important decision, then they realize that they are ignored, and then their level of stress and confusion surge, their engagement with the work plummets (Sommer, \& Baumeister, 1995). Workplace ostracism affects that type of employees which have neuroticism personality because they are very emotional, they feel demotivated from this ignorance in the workplace (Hitlan, 2014).

\subsection{Research Problem}

The workplace ostracism happens when employees feel that their work colleagues are ignoring them; the workplace ostracism has various negative impacts such as negative organizational culture, organizational commitment, and efficiency of employees. But in our research we tested the relationship of workplace ostracism on stress and employee engagement, therefore "The aim of this research was to find out the impact of workplace ostracism on stress and employee engagement"

\subsection{Objectives of the study}

- To test the impact of workplace ostracism on stress.

- To explain the impact of workplace ostracism on employee engagement.

\section{Literature Review}

Workplace ostracism effect on employee's stress, employee engagement and commitment, because employees will think other employees ignore them so how can they survive in this environment where the other employees are not giving them value, it will affect organization's outcomes as well (Chung, 2017), (Hitlan, \& Noel, 2009). If workplace ostracism is happening with employees then it will be the reason for low interaction between the employees. Moreover, it will negatively affect employee's engagement because when employees have amicable relation then they can share their work environment problems and information. It can also increase work productivity because some tasks are hard for some employees as they have not required skills, they have to ask from seniors, if the senior is ignoring them in the workplace then it will have negative result on organization performance, the junior employees will never go to that type of senior employees after being ostracized. Social connection of the work environment will decrease because of this ostracized behavior (Reilly, \& Wang, 2012). One research also shows that if there is workplace ostracism in the organization, it can affect employee's performance because the other employees miss out the advice for his work betterment (Sparrowe, Liden, Wayne, \& Kraimer, 2001). One of the greatest menace for productivity of any employee is stress. Stress effects employees' performance because when employees are mentally disturbed, they cannot perform the task with full efforts; the employees' performance needs specific energy and specific mental relaxation, which is a basic requirement of every work task (Detert, \& Burris, 2007). One study found that the workplace ostracism negatively effect on the employee's emotions, such as stress, depression, unhappiness, loneliness, that all emotional status after workplace ostracism affect the employees' performance because the emotionally hurt persons cannot perform their task with creative ideas ( Gruter, \& Masters, 1986; Williams, 2002).

\subsection{Workplace Ostracism}

Ostracism is a word that is derived from the ancient Greek word "ostrakimos" which was used to explain the practice of removing those with despotic aspiration from the democratic state (Zippelius, 1986). Work ostracism contains avoiding eye contact, intended isolation, neglect, or ignore the ostracized person $(\mathrm{Wu}$, 2010). Workplace ostracism harms organizational citizenship culture (Reilly \& Robinson, 2009). Ostracism involves at least two parties, perpetrators and targets (Williams, 1997). Workplace is one of the most important social contexts where ostracism takes place; some studies have found that workplace ostracism harms attitude and behavior (Fox \& Stallworth, 2005). Researchers have not provided the mechanism that 


\section{A. H. Samo - S. Khan - N. Ali - S. Ali 11/4 (2019) 3471-3484}

can further explain the relationship, but they have suggested few potential mediators that can further help to understand the effect of workplace ostracism (Zhao, Peng, \& Sheard, 2013). Few studies have inspected a direct impact on workplace ostracism to various attitudinal and behavioral outcomes such as psychological well-being, job attitudes, job withdrawal, and workplace deviant behavior (Hitlan, \& Noel, 2009). It has been observed that there are practical and psychological effects that can mediate the relationships between workplace ostracism and behavioral outcomes such as job performance, organizational citizenship behavior, and deviant behavior (Robinson, 2013). Workplace ostracism threatens four fundamental human needs: the need for self-esteem, the need to belong, the need to control, and the need for a meaningful existence (Williams, 1997). First, self-esteem is affected by ostracism because when the individual is ignored then definitely that person will think that he/she has done something wrong, or that person has some negative attributes that causes this. Ostracism has a negative impact on self-esteem. Second, Ostracism has a negative impact on the need to belong because the individual feels that he is removed from the group which he wants to be a part of. Third, individuals have a sense of control erode because others' bad actions cannot be treated to their good actions. Last but not the least, sense of a meaningful existence is affected by ostracism because it represents a social death and shows that how life would be when one does not exists (Sommer, 2001). When an individual or group withholds the other person, which causes engage to another organizational member due to this work, ostracism occurs; as far as society is concerned, it is appropriate to do so (Robinson, Reilly, \& Wang, 2013). Workplace ostracism increases employee turnover, and it ultimately decreases the performance of the organization (Hitlan, Cliffton, \& Desoto, 2006). Endanger employee relationships (Gerber \& Wheeler, 2014), and reduce employees' personal and work satisfaction (Ferris, 2008). Recent studies suggest that individuals are ostracized on a daily basis (Nezlek, Wesselmann, Wheeler, \& Williams, 2015). Work ostracism indicates to the focal person that he or she is not acceptable by the organization and it may reduce the employee's sense of belonging (Williams, 2007). An employee speaks when they feel that their point of view gets valued in the organization (Parker, Bindl, \& Strauss, 2010).

\subsection{Stress}

Stress is a situation when a person is suffering from mental disturbances and can not do something productive and also generate negative emotions (Mullan, 2014). Stress is the reason for bad health and illness of a person, and stress also increases job dissatisfaction of a person (Mathisen, Einarsen, \& Mykletun, 2011). Stress is also a reason for the aggressive behavior of a person, and stress also leads to the negative behavior of an employee at the workplace (Ferris, Brown, Berry, \& Lian, 2008). Due to stress, an employee cannot make good relationships in the workplace, and he will not find a friendly environment in the workplace because of stress ( Attell, Kummerow, \& Treiber, 2017; Turner \& Turner, 2013). Stress negatively affects the mental health of the person and individual want social support when he suffers stress situation, also emotional and physical help from the other in a stress situation. The individual is in a situation of stress wants attention from other people because they themselves feel low and need the support of their colleagues. (Hogh, Hansen, Mikkelsen, \& Persson, 2012). According to the research, there is moderating role of social class of the employee, the more downwards the class more the effect of stress on the employees (Mullan, 2014). An individual has less social support in their professional life or personal life. He will face problems, and these problems lead to stress, and this support comes from friends and family (Donnell \& Macintosh, 2015). Stress will also lead to misbehaving with coworkers so at workplace an employee wants social support from his coworkers to decrease his stress level at the workplace (Thoits, 2011). Stress also affects negatively to productivity of an employee, effectiveness of an employee, and decreases the level of quality of his work, a person has a high level of stress will make unfavorable situation for him and also decrease his energy level which he wants to perform his tasks related to the job or in personal life (Savery, Luks, Savery, \& Luks, 2011). Stress can also destroy the contextual behavior of a person such as the helping other peoples the behavior of voice stress will negatively affect all the good behaviors of a person because individual who suffer stress will try to protect his physical and emotional energy time in stress (Chung, 2018). In normal situation an individual will avoid the situation in which there is the presence of probability of his loss but in stress he is unable to understand that what is good, and what is bad for him and he will not understand the situation, therefore, probability of loss will be high (Schilpzand, Leavitt, \& Lim, 2016). Stress is one of those factors which reduces the productivity of an employee in organization stress reduces the level of the productivity at large amount, and some researchers found that there is a direct relationship between stress and the performance of an employee (Mathisen et al., 2011). Stress can be managed at the workplace 


\section{A. H. Samo - S. Khan - N. Ali - S. Ali 11/4 (2019) 3471-3484}

the approach which should be used to manage the stress is a good behavior of a manager with the employees in order to minimize the stress level of an employee manager can play an important role (Matin, Razavi, \& Campus, 2014).

\subsection{Employee Engagement}

Employee engagement is a hot topic for the organization as well as academic sectors, William Kahn is presented first this concept in 1990, when organization manages their employees according to their job role which can lead them to work for their organization as enthusiastically then employee will contribute their efforts towards organization success (Kahn, 1990). Today, organizations recognize that the employee engagement can stimulate higher performance, customer satisfaction, organization productivity, employee retention, and an organization has a competitive advantage if it has engaged employees (Harter, Schmidt \& Hayes, 2002).

There are three core facets of employee engagement (Alfes, 2010);

1. Intellectual Engagement: In these facets, the employee mentally engage with the organization, employee think about an organization's continuous improvement, and the employee utilizes knowledge to provide ideas towards the betterment of the organization.

2. Social Engagement: when employee is ready to share ideas with other employees and employers towards the betterment of the organization, that the time of employee promotes teamwork in an organization which increases the organizational productivity.

3. Affective Engagement: When employees have positive feelings about their organization; they think the organization has given us lots of benefits. Therefore, we should be loyal with them towards organization betterment and success.

The reason that organizations invest time and money to cultivate the culture of work engagement is because it is linked with other organization factors, performance of employee, friendly climate of organization and profit for organization, for instance, if the employees are engaged they will deal customer nicely that customer will visit store again to purchase your products, it will generate revenue which will contribute to the organization`s profit then the organization revenue will grow (Towers \& Perrin, 2003). Employee engagement is also a reason for good health and satisfaction for employee because an organization consider the employment decisions and also share the organization major problems and success with employees then employee feel that they are valued by organization, it results in positive feelings to employee as well as it is beneficial for organization because happy and healthy employees are more productive as compared unhappy and unhealthy employees (Mauno, Kinnunen, \& Ruokolainen, 2007). Employee engagement is a relationship between employee and organization; how much the relation will strong, then there will be more probability of organization success because engaged employees have a strong emotional feeling about their organization; they contribute high-performance work, time, and efforts for organization success (Quirke, 2008). One study found that the starting year of the employee job is very crucial for the organization to engage that employee with organization, provide them training about their job, provide them orientation as like they feel friendly, get feedback from employees and give time to them and listen their issues regarding their work and organization, this small efforts of the organization will give them future years of commitment employees (Trahant, 2009). The supervisor has a major role to engaged the employees, because the supervisor is the only person who directly links with employees, therefore the supervisor have to communicate organizational goals effectively then the employees will achieve organizational goals efficiently, because when the employees do not understand the goals clearly then how can they achieve them, they will make mistakes, the result will be low performance, and low employee engagement with organization (Saks, 2006).

\subsection{Relationship between Workplace Ostracism, Stress and Employee Engagement}

This research is about to find out the relationship or impact between workplace ostracism on stress and employee engagement, workplace ostracism negatively affect the human behavior at the workplace, and there is a positive relationship between the workplace ostracism and deviant behavior of the employee (Ferris, 2008). Workplace ostracism increases the stress level of an individual and decreases the ability to 


\section{A. H. Samo - S. Khan - N. Ali - S. Ali 11/4 (2019) 3471-3484}

perform the task related to the job, in a situation of stress an individual loses the ability to maintain his performance and also self-regulation is needed to perform his task which he loses because of the stress (Williams, Bernieri, \& Faulkner, 2001). The workplace ostracism also enhances the negative emotion of an individual such as mental illness, depression, sadness, jealousy, shame, guilt, embracement. These all emotions lead an individual towards stress; the stress situation minimizes the self-awareness of an individual a person doesn't know how to react in a present situation (Attell, 2017). The workplace ostracism also has a negative impact on employee engagement at the workplace because of ostracism; the communication gap will be increased between the employees (Saver, 2011). Workplace ostracism is also the reason for workplace conflict the aggressive behavior of the employee which makes employees' uncomfortable and they might decrease the interaction with other employees because of the negative environment at the workplace (Cremer \& Hiel, 2006). The workplace ostracism also decreases the overall performance of the employees and organization because an employee cannot give his best performance if he is part of workplace ostracism or negative workplace environment, which made because of the workplace ostracism (Chung, 2018). Workplace ostracism have impact on stress it means that ostracized employees are likely to have experience of stress, anxiety, and depression (Ferris, 2008) and they also layout withdrawal behavior, and have less satisfaction to their jobs, which leads them to less productive and engagement in their jobs because when an employee is ignored in the organization then he will think that he will not be able to engage himself in his work. (Lustenberger \& Jagacinski, 2010). Basically, ostracism is an interpersonal stressor (Williams, 2001), which often responsible for obdurate reactions and anti-social behavior (Warburton, 2006). Few researchers have highlighted that ostracism acts as an uncontrollable stressor that usually harms the person, threatens, and challenges their well-being (Latack \& Havlovic, 1992). Workplace ostracism decreases employee engagement, which ultimately reduces the service level of employees; it means that when the employee is ostracized, it will have a negative impact on customer satisfaction because the employee will not be able to engage himself in work (Leung, 2011). Workplace ostracism has a positive relation to burnout and turnover intentions and is negatively related to job satisfaction, employee engagement and organizational commitment (Nielsen \& Einarsen, 2012). Employees who find themselves in work engagement tend to identify themselves with their work and have high levels of energy (Bakker, Schaufeli, Leiter, \& Taris, 2008). Workplace ostracism decreases work engagement of employees; it means that there is a negative relationship between workplace ostracism and employee engagement (Glasø, Bele, Nielsen, \& Einarsen, 2011). (Reio \& Sanders, 2011).

The research gap we have found that this research has been done in other countries but they tested workplace ostracism on other variables but we tested on different variables and in our country this research is not done by anyone on banking sector, so it is a big advantage for banking sector to get help from this research which will be helpful for them to manage workplace ostracism in banks.

\subsection{Hypothesis}

H1. There is a positive impact of workplace ostracism on stress.

H2. There is a negative impact of workplace ostracism on employee engagement.

Independent Variables

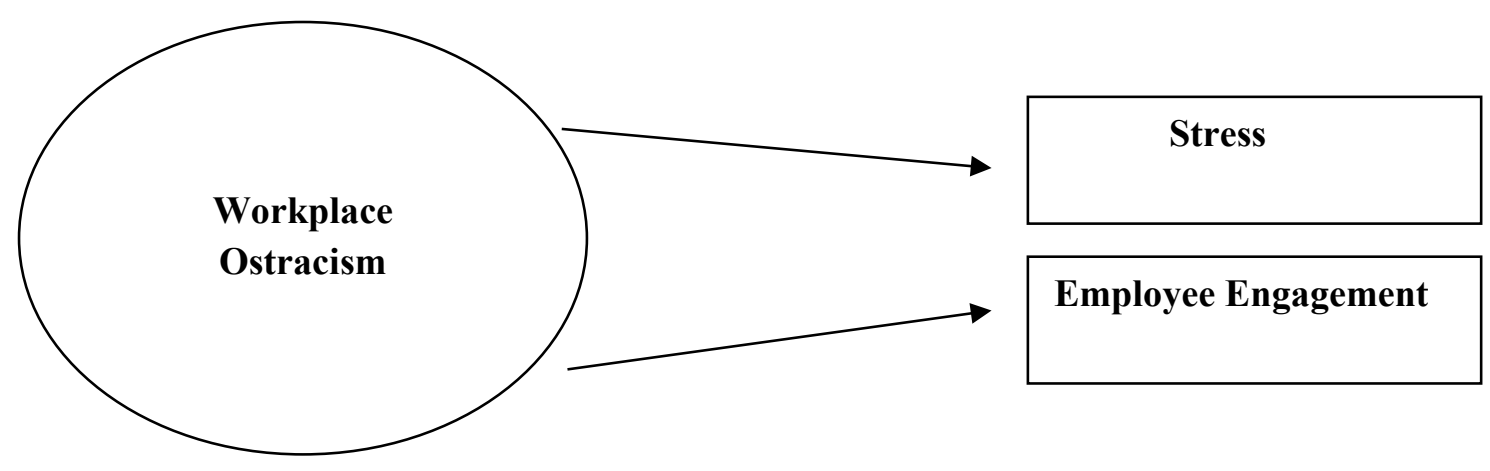




\section{A. H. Samo - S. Khan - N. Ali - S. Ali 11/4 (2019) 3471-3484}

\section{Research Methodology}

\subsection{Research Model}

This research is quantitative in nature and completed by collecting numerical data, the numeric data collected through primary sources for this we adopted questionnaire from research articles which were filled by the employees of the banking sector of Karachi. The result of this data made through SPSS software.

\subsection{Population}

Employees who are working in the banking sector in Karachi, such as cashier, accountant, operation manager, customer relationship officer, customer services manager, credit analyst.

\subsection{Sample and Sampling Methods}

This research is purely quantitative in nature, and the data collected through primary sources and questionnaires filled from 330 employees who are working in the banking sector of Karachi. We used nonprobability convenient sampling in order to collect the data in this research.

\subsection{Instrument Selection}

Through questionnaire we collected primary data, questionnaire were closed-ended, we adopted instrument from previous research papers, and questionnaires were based on three variables: Workplace Ostracism (Ferris, 2008) , Stress (Parker, 1983) and Employee Engagement (Vale, 2011),

\subsection{Plan of Analysis}

We performed diagnosis tests such as Cronbach alpha to check the reliability and we also tested correlation. For hypotheses testing, we performed regression analysis.

4. Findings

The result of Workplace Ostracism and Stress

Table 4.1: Model Summary

\begin{tabular}{ccc}
\hline 1 & $.427^{\mathrm{a}}$ & .182 \\
\hline Model & $\mathrm{R}$ & R Square \\
\hline
\end{tabular}

a. Predictors (constant): Workplace Ostracism

b. Dependent variable: Stress

As it has been mentioned in above table 4.1, the value of $\mathrm{R}$ Square is .182, which explains that Workplace ostracism is explaining $18.2 \%$ variance in Stress.

Table 4.2: Correlations Between the Constructs

Pearson correlation

$\begin{array}{ccc}\text { Stress } & 1.000 & .427 \\ \text { Workplace Ostracism } & .427 & 1.000\end{array}$

Sig. (1-tailed)

Stress

.000

Workplace ostracism $\quad 0.000$

Stress Workplace Ostracism

The link between Workplace Ostracism and Stress was examined and utilizing the Pearson feature short time connection coefficient presented in table 4.2. There is a strong positive relationship between Workplace Ostracism with Stress as well. Values for Workplace Ostracism .427p-value less than 0.005 , showing that the Workplace Ostracism highly affected the Stress. 
A. H. Samo - S. Khan - N. Ali - S. Ali 11/4 (2019) 3471-3484

Table 4.3: Coefficients

\begin{tabular}{lcccc}
\hline $1 \quad$ (Constant) & 26.213 & 1.658 & & 0.000 \\
Workplace & .369 & .043 & .427 & 0.000 \\
Ostracism & & & \\
\hline & \multicolumn{3}{c}{ Unstandardized Coefficient } & Standardized \\
& & Coefficient & Sig. \\
\hline
\end{tabular}

a. Dependent variable: Stress

The impact of workplace ostracism on stress was measured, table 4.3, that the beta value for Workplace Ostracism .427, which means that Workplace Ostracism constructs a solid, unique contribution to explain the Stress.

Descriptive Statistics

Table 1: Age

\begin{tabular}{lrrrr}
\hline & Frequency & Percent & Valid Percent & Cumulative Percent \\
\hline $20-25$ & 20 & 6.1 & 6.1 & 6.1 \\
$26-30$ & 64 & 19.4 & 19.4 & 25.5 \\
$31-35$ & 65 & 19.7 & 19.7 & 45.2 \\
$36-40$ & 55 & 16.7 & 16.7 & 61.8 \\
$41-45$ & 42 & 12.7 & 12.7 & 74.5 \\
$46-50$ & 34 & 10.3 & 10.3 & 84.8 \\
$51-$ above & 50 & 15.2 & 15.2 & 100.0 \\
Total & 330 & 100.0 & 100.0 & \\
\hline
\end{tabular}

The above table shows that the 31-35 age employees filled more form as compared to other age groups, and the minimum age group is the 20-25 age group who filled forms.

Table 2: Gender

\begin{tabular}{lrrrr}
\hline & Frequency & Percent & Valid Percent & Cumulative Percent \\
\hline Male & 218 & 66.1 & 66.1 & 66.1 \\
Female & 112 & 33.9 & 33.9 & 100.0 \\
Total & 330 & 100.0 & 100.0 & \\
\hline
\end{tabular}

In the above table mentioned that from 330 forms, $66.1 \%$ were male, and $33.9 \%$ were female.

Table 3: Year of Experience

\begin{tabular}{lrrrr}
\hline & Frequency & Percent & Valid Percent & Cumulative Percent \\
\hline 1 Year-or Less & 10 & 3.0 & 3.0 & 3.0 \\
$2-5$ & 72 & 21.8 & 21.8 & 24.8 \\
$6-9$ & 53 & 16.1 & 16.1 & 40.9 \\
$10-13$ & 66 & 20.0 & 20.0 & 60.9 \\
$14-17$ & 50 & 15.2 & 15.2 & 76.1 \\
$18-$ and above & 79 & 23.9 & 23.9 & 100.0 \\
Total & 330 & 100.0 & 100.0 & \\
\hline
\end{tabular}

In the above table mentioned that minimum experience is 1 year or less is $3.0 \%$ and maximum experience 18 and above is $23.9 \%$ in our 330 total form data collection. 
A. H. Samo - S. Khan - N. Ali - S. Ali 11/4 (2019) 3471-3484

The result of Workplace Ostracism and Engagement

Table 1: Model Summary

\begin{tabular}{ccc}
\hline 1 & $.626^{\mathrm{a}}$ & .392 \\
\hline Model & $\mathrm{R}$ & R Square \\
\hline
\end{tabular}

a. Predictors (constant): Workplace Ostracism

b. Dependent variable: Employee Engagement

Table-1: Interpretation

As it has been mentioned in the above table named as a model summary, the value of $R$ Square is .392, which means that Workplace ostracism is describing 39\% variance in employee engagement.

Table 2: Correlations

\begin{tabular}{llcc}
\hline Pearson correlation & & Employee Engagement & Workplace Ostracism \\
\hline & Employee Engagement & 1.000 & -.626 \\
& Workplace Ostracism & -.626 & 1.000 \\
Sig. (1-tailed) & & & .000 \\
& Employee Engagement & & \\
& Workplace ostracism & 0.000 & \\
\hline
\end{tabular}

Table-2: Interpretation

The link between Workplace Ostracism and employee engagement was examined and utilizing Pearson feature short term time connection coefficient. There is a negative relationship between Workplace Ostracism with employee engagement as well. Values for Workplace Ostracism. -.626 p-value less than 0.005 showing that the Workplace Ostracism highly affected employee engagement.

Table-3: Interpretation

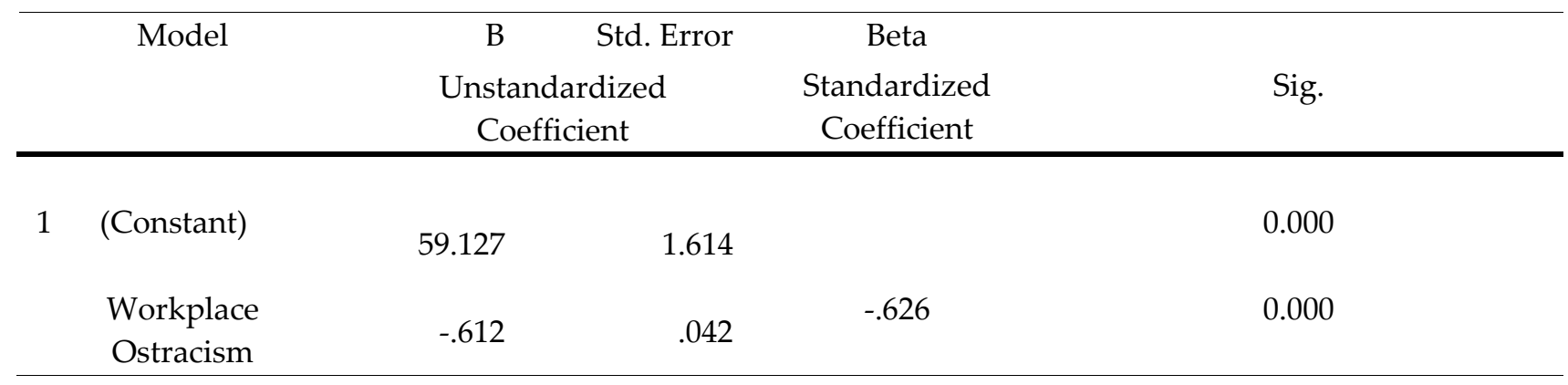

Dependent variable: Employee Engagement

As it has been mentioned in the above table, we can see that the beta value for Workplace Ostracism -.626 which means that Workplace Ostracism makes the strongest unique contribution to explain the Employee Engagement

\section{Reliability Statistics}

\begin{tabular}{llll}
\hline 01 & Workplace Ostracism & 0.910 & 11 \\
02 & Employee Engagement & 0.936 & 12 \\
03 & Stress & 0.886 & 13 \\
\hline S.\# & Construct & Cronbach Alpha & No \\
\hline
\end{tabular}




\section{Discussion}

\section{Ostracism Impact on Stress}

The results found that workplace ostracism has a positive impact on Stress. The relationship between Workplace Ostracism and Stress was examined utilizing the Pearson feature short time connection coefficient. Preparatory investigations were performed to guarantee no infringement of the suspicious of typicality, linearity, and homoscedasticity. There is a strong positive relationship between Workplace Ostracism with Stress as well. Values for Workplace Ostracism .427p-value less than 0.005 , showing that the Workplace Ostracism highly affects Stress. The value of R Square is .182 which means that Workplace ostracism is explaining $18.2 \%$ variance in Stress. The beta value for Workplace Ostracism is .427 which means that Workplace Ostracism makes the strongest unique contribution to explain the Stress.

The finding of one study suggests that there is a positive impact of workplace Ostracism on Stress and we have also found that the workplace ostracism has positive impact on stress, But in that research they have found that Stress has positive impact on organization outcomes, but we have found that there is negative impact on organization outcomes because of stress, job tension, emotional exhaustion, and depressed mood at work. (Wu, 2011).

Previous studies have found that workplace ostracism to be positively related to task conflict, colleague's conflict, manage conflict, and supervisor conflict. We have also found a similar result as they have found because workplace Ostracism has a positive impact on employee stress and negative impact on Employee Engagement; because of conflicts, the employee will face Stress, and also it will reduce Employee Engagement.(Chung,2015)

\section{Ostracism Impact on Employee Engagement}

The results revealed that workplace ostracism has a negative impact on employee engagement. The relationship between Workplace Ostracism and Employee Engagement was examined utilizing the Pearson feature short time connection coefficient. Preparatory investigations were performed to guarantee no infringement of the suspicious of typicality, linearity, and homoscedasticity. There is a negative relationship between Workplace Ostracism with employee engagement as well. The values for Workplace Ostracism. Is .626 p-value less than 0.005 showing that the Workplace Ostracism highly affects Employee Engagement. The value of $\mathrm{R}$ Square is .392 which means that Workplace ostracism is explaining $39.2 \%$ variance in employee engagement. From the above table, we can see that the beta value for Workplace Ostracism is -.626 which means that Workplace Ostracism makes the strongest unique contribution to explain Employee Engagement.

The objective of our study is to find out the gap between workplace Ostracism and one's personality contribution to work engagement and service performance. (Hobfall, 1998). In previous researches, the employee engagement variable was used as a mediating variable between workplace ostracism and service performance. In our study, we considered Employee Engagement as a dependent variable. The result was similar to the previous researches have because of the workplace. Ostracism has a negative impact on Service Performance and Employee Engagement (Hitlan and Noel's, 2009).

One of the research indicates the direct effect of Workplace Ostracism on the health of workers remained significant, whereas the direct effect of Workplace Ostracism on Employee engagement was reduced. These results show that job insecurity is an important additional element in linking workplace Ostracism with its relevant outcome variables. Our results also show that there is a negative impact of workplace ostracism on employee engagement because when workplace ostracism occurred employee engagement in an organization is decreased because the employee feels the organization is not valuing me. (Park, 2016).

\section{Implications and Conclusion}

\section{Implications}

The theoretical implication of this study, our results of this study reinforce the past theories about workplace ostracism, stress, and employee engagement because the results are similar to past research results. The results of this study are helpful for employees, organizations, managers, and supervisors because supervisor 


\section{A. H. Samo - S. Khan - N. Ali - S. Ali 11/4 (2019) 3471-3484}

and managers supervise all the employees of the organization and from this research, they will know that ostracism increases risk and decreases the employee engagement, so they will work on it to maintain the good environment at the workplace. It is also possible that individual factors such as extrovert skills will not only help to deal with workplace ostracism but also other difficult situations at work like abusive supervision bad behavior. The employees who face workplace ostracism has a higher level of psychological stress, and it may become the reason of the potential health problem of the employees and because of this employees may involve in the negative act at the workplace and also our results showed that the workplace ostracism reduces the employee engagement. In practical implication, the stress is costly for both organizations and also managers because of workplace ostracism; the productivity of employees decreases. There are two ways to reduce the level of stress one decreasing workplace ostracism, and second is give training sessions to the employees who are facing workplace ostracism.

\section{Conclusion}

Workplace Ostracism has a positive effect on stress because it increases the stress of employees, which are ostracized, and workplace ostracism has a negative effect on employee engagement because it reduces engagement of the employees on work. The purpose of this study is to find out the impact of workplace ostracism on stress and employee engagement, and we have concluded that there is a positive impact of workplace ostracism on stress, and there is the negative impact of workplace ostracism on engagement.

\section{Future Research}

We have concluded our study, and in the end, we have concluded that there is room for future research that impacts of workplace ostracism on employee performance, organizational culture, employee commitment, employee retention.

\section{References}

Attell, B. K., Kummerow Brown, K., \& Treiber, L. A. (2017). Workplace bullying, perceived job stressors, and psychological distress: Gender and race differences in the stress process. Social Science Research, 65, 210-221. doi:10.1016/j.ssresearch.2017.02.001

Alfes, K., Truss, C., Soane, E., Rees, C., \& Gatenby, M. (2010). Creating an engaged workforce: findings from the Kingston employee engagement consortium project.

Bakker, A. B., Schaufeli, W. B., Leiter, M. P., \& Taris, T. W. (2008). Work engagement: An emerging concept in occupational health psychology. Work \& Stress, 22(3), 187-200.

Bang, O. Y., Saver, J. L., Kim, S. J., Kim, G. M., Chung, C. S., Ovbiagele, B., ... \& Liebeskind, D. S. (2011). Collateral flow predicts response to endovascular therapy for acute ischemic stroke. Stroke, 42(3), 693-699.

Baumeister, R. F., \& Sommer, K. L. (1997). What do men want? Gender differences and two spheres of belongingness: Comment on Cross and Madson (1997).

Carter-Sowell, A. R., Chen, Z., \& Williams, K. D. (2008). Ostracism increases social susceptibility. Social Influence, 3(3), 143-153.

Chung, Y. W. (2018). Workplace ostracism and workplace behaviors: A moderated mediation model of perceived stress and psychological empowerment. Anxiety, Stress, \& Coping, 31(3), 304-317. doi:10.1080/10615806.2018.1424835

Cohen, S. (1980). Aftereffects of Stress on Human Performance and Social Behavior: A Review of Research and Theory, 88(1), 82-108.

Cohen, S., Kamarck, T., Mermelstein, R., Health, J., Behavior, S., \& Dec, N. (2008). A Global Measure of Perceived Stress A Global Measure of Perceived Stress, 24(4), 385-396.

Cremer, D. De, \& Hiel, A. Van. (2006). Effects of another person's fair treatment on one's own emotions and behaviors: The moderating role of how much the other cares for you. Organizational Behavior and Human Decision Processes, 100(2), 231-249.

Dupas, P., \& Robinson, J. (2013). Savings constraints and microenterprise development: Evidence from a field experiment in Kenya. American Economic Journal: Applied Economics, 5(1), 163-92. 


\section{A. H. Samo - S. Khan - N. Ali - S. Ali 11/4 (2019) 3471-3484}

Detert, J. R., \& Burris, E. R. (2007). Leadership behavior and employee voice: Is the door really open?. Academy of management journal, 50(4), 869-884.

Ferris, D. L., Brown, D. J., Berry, J. W., \& Lian, H. (2008). The Development and Validation of the Workplace Ostracism Scale, 93(6), 1348-1366.

Fox, S., \& Stallworth, L. E. (2005). Raciall/ethnic bullying: Exploring links between bullying and racism in the US workplace. Journal of Vocational Behavior, 66(3), 438-456.

First, M. B., Spitzer, R. L., Gibbon, M., \& Williams, J. B. (1997). User's guide for the Structured clinical interview for DSM-IV axis I disorders SCID-I: clinician version. American Psychiatric Pub.

Grandey, A. A., \& Cropanzano, R. (2000). The Conservation of Resources Model Applied to Work - Family Conflict and Strain, 370(1999), 350-370.

Gerber, J. P., Chang, S. H., \& Reimel, H. (2017). Construct validity of Williams' ostracism needs threat scale. Personality and Individual Differences, 115, 50-53.

Gupta, N., \& Sharma, V. (2016). Exploring Employee Engagement-A Way to Better Business Performance. Global Business Review, 17, 45S-63S.

Glasø, L., Bele, E., Nielsen, M. B., \& Einarsen, S. (2011). Bus drivers' exposure to bullying at work: An occupation-specific approach. Scandinavian journal of psychology, 52(5), 484-493.

Gerber, J. P., \& Wheeler, L. (2014). Clarifying the relationship between ostracism and relational devaluation. The Journal of Social Psychology, 154(1), 14-27.

Gruter, M., \& Masters, R. D. (1986). Ostracism as a social and biological phenomenon: An introduction.

Hitlan, R. T., \& Noel, J. (2009). The influence of workplace exclusion and personality on counterproductive work behaviours: An interactionist perspective. European Journal of Work and Organizational Psychology, 18(4), 477-502.

Hansen, M. N., Henriksen, K., \& Sommer, S. G. (2006). Observations of production and emission of greenhouse gases and ammonia during storage of solids separated from pig slurry: effects of covering. Atmospheric Environment, 40(22), 4172-4181.

Howes, J. C., Cropanzano, R., Grandey, A. A., \& Mohler, C. J. (2000). Who is supporting whom?: Quality team effectiveness and perceived organizational support. Journal of Quality Management, 5(2), 207223.

Halkos, G., \& Bousinakis, D. (2010). The effect of stress and satisfaction on productivity. International Journal of Productivity and Performance Management, 59(5), 415-431.

Hogh, A., Hansen, Å. M., Mikkelsen, E. G., \& Persson, R. (2012). Exposure to negative acts at work, psychological stress reactions and physiological stress response. Journal of Psychosomatic Research, 73(1), 47-52.

Hudac, C. M. (2018). Social priming modulates the neural response to ostracism: a new exploratory approach. Social Neuroscience, 1-15.

Heaphy, e. D., \& dutton, j. E. (2008). Positive social interactions and the human body at work: linking organizations and physiology, 33(1), 137-162.

Harter, J. K., Schmidt, F. L., \& Hayes, T. L. (2002). Business-unit-level relationship between employee satisfaction, employee engagement, and business outcomes: A meta-analysis. Journal of applied psychology, 87(2), 268.

Hobfall, S. E. (1998). Stress culture, and the community 02 New York.

Hitlan, R. T., Cliffton, R. J., \& DeSoto, M. C. (2006). Perceived exclusion in the workplace: The moderating effects of gender on work-related attitudes and psychological health. North American Journal of Psychology, 8(2), 217-236.

Jahanzeb, S., \& Fatima, T. (2017). How Workplace Ostracism Influences Interpersonal Deviance: The Mediating Role of Defensive Silence and Emotional Exhaustion. Journal of Business and Psychology, 113.

Kahn, W. A. (1990). Psychological conditions of personal engagement and disengagement at work. Academy of management journal, 33(4), 692-724. 


\section{A. H. Samo - S. Khan - N. Ali - S. Ali 11/4 (2019) 3471-3484}

Leung, A. S. M., Wu, L. Z., Chen, Y. Y., \& Young, M. N. (2011). International Journal of Hospitality Management The impact of workplace ostracism in service organizations, 30, 836-844.

Latack, J. C., \& Havlovic, S. J. (1992). Coping with job stress: A conceptual evaluation framework for coping measures. Journal of organizational behavior, 13(5), 479-508.

Lustenberger, D. E., \& Jagacinski, C. M. (2010). Exploring the effects of ostracism on performance and intrinsic motivation. Human Performance, 23(4), 283-304.

Mauno, S., Kinnunen, U., \& Ruokolainen, M. (2007). Job demands and resources as antecedents of work engagement: A longitudinal study. Journal of vocational behavior, 70(1), 149-171.

Mok, A., \& De Cremer, D. (2015). The bonding effect of money in the workplace: priming money weakens the negative relationship between ostracism and prosocial behavior. European Journal of Work and Organizational Psychology, 25(2), 272-286.

Motowidlo, S. J., Packard, J. S., \& Manning, M. R. (1986). Occupational Stress : Its Causes and Consequences for Job Performance, 71(4), 618-629.

Mathisen, G. E., Einarsen, S., \& Mykletun, R. (2011). The Relationship Between Supervisor Personality, Supervisors' Perceived Stress and Workplace Bullying. Journal of Business Ethics, 99(4), 637-651. https://doi.org/10.1007/s10551-010-0674-z

Matin, H. Z., Razavi, H. R., \& Campus, F. (2014). Is stress management related to workforce productivity?, (October 2012), 1-19.

Mishra, K., Boynton, L., \& Mishra, A. (2014). Driving Employee Engagement. International Journal of Business Communication, 51(2), 183-202.

Mullan, B. A. (2014). Sleep, stress and health: A commentary. Stress and Health, 30(5), 433-435. https://doi.org/10.1002/smi.2605

Mathisen, G. E., Einarsen, S., \& Mykletun, R. (2011). The relationship between supervisor personality, supervisors' perceived stress and workplace bullying. Journal of Business Ethics, 99(4), 637-651.

Nezlek, J. B., Wesselmann, E. D., Wheeler, L., \& Williams, K. D. (2015). Ostracism in everyday life: The effects of ostracism on those who ostracize. The Journal of social psychology, 155(5), 432-451.

Nielsen, M. B., \& Einarsen, S. (2012). Outcomes of exposure to workplace bullying: A meta-analytic review. Work \& Stress, 26(4), 309-332.

Nagtegaal, I. D., \& Quirke, P. (2008). What is the role for the circumferential margin in the modern treatment of rectal cancer?. Journal of Clinical Oncology, 26(2), 303-312.

O’Donnell, S. M., \& MacIntosh, J. A. (2016). Gender and workplace bullying: men's experiences of surviving bullying at work. Qualitative health research, 26(3), 351-366

Parker, S. K., Bindl, U. K., \& Strauss, K. (2010). Making things happen: A model of proactive motivation. Journal of management, 36(4), 827-856.

Parker, D. F., \& DeCotiis, T. A. (1983). Organizational determinants of job stress.

Park, J. H., \& Ono, M. (2016). Effects of workplace bullying on work engagement and health: the mediating role of job insecurity. The International Journal of Human Resource Management, 28(22), 3202-3225.

Qian, J., Yang, F., Wang, B., Huang, C., \& Song, B. (2017). When workplace ostracism leads to burnout: the roles of job self-determination and future time orientation. The International Journal of Human Resource Management, 5192(December), 0.

Rana, S. (2015). High-involvement work practices and employee engagement. Human Resource Development International, 18(3), 308-316.

Ren, D., Wesselmann, E. D., \& Williams, K. D. (2018). Hurt people hurt people: ostracism and aggression. Current Opinion in Psychology, 19(17), 34-38. https://doi.org/10.1016/j.copsyc.2017.03.026

Robinson, S. L., O'Reilly, J., \& Wang, W. (2012). Invisible at Work. Journal of Management, 39(1), $203-231$. doi:10.1177/0149206312466141

Reio Jr, T. G., \& Sanders-Reio, J. (2011). Thinking about workplace engagement: does supervisor and coworker incivility really matter?. Advances in Developing Human Resources, 13(4), 462-478. 


\section{A. H. Samo - S. Khan - N. Ali - S. Ali 11/4 (2019) 3471-3484}

Robinson, S. L., O'Reilly, J., \& Wang, W. (2013). Invisible at work: An integrated model of workplace ostracism. Journal of Management, 39(1), 203-231.

Robinson, S. L., O’Reilly, J., \& Wang, W. (2012). Invisible at Work. Journal of Management, 39(1), 203-231.

Savery, L. K., \& Luks, J. A. (2001). The relationship between empowerment, job satisfaction and reported stress levels: some Australian evidence. Leadership \& Organization Development Journal, 22(3), 97-104.

Schilpzand, P., Leavitt, K., \& Lim, S. (2016). Incivility hates company: Shared incivility attenuates rumination, stress, and psychological withdrawal by reducing self-blame. Organizational Behavior and Human Decision Processes, 133, 33-44.

Sparrowe, R. T., Liden, R. C., Wayne, S. J., \& Kraimer, M. L. (2001). Social networks and the performance of individuals and groups. Academy of management journal, 44(2), 316-325.

Saks, A. M. (2006). Antecedents and consequences of employee engagement. Journal of managerial psychology, 21(7), 600-619.

Schilpzand, P., Leavitt, K., \& Lim, S. (2016). Incivility hates company: Shared incivility attenuates rumination, stress, and psychological withdrawal by reducing self-blame. Organizational Behavior and Human Decision Processes, 133, 33-44

Thoits, P. A. (2011). Mechanisms linking social ties and support to physical and mental health. Journal of Health and Social Behavior, 52(2), 145-161.

Turner, J. B., \& Turner, R. J. (2013). Handbook of the Sociology of Mental Health, 341-356.

Trahant, B. (2009). Driving better performance through continuous employee engagement. Public Manager, 38(1), 54 .

Towers, P. (2003). Working today: Understanding what drives employee engagement. Towers Perrin: Stamford CT.

Vale, (2011). A Measurement of Employee Engagement Using the Gallup Q12 Workplace Audit (Doctoral dissertation, Dublin, National College of Ireland).

Valaei, N., \& Rezaei, S. (2016). Job satisfaction and organizational commitment. Management Research Review, 39(12), 1663-1694.

Williams, K. D., Bernieri, F. J., \& Faulkner, S. L. (n.d.). Journal of Personal and Interpersonal Loss: International Perspectives on Stress \& Coping The Scarlet Letter Study: Five Days of Social Ostracism, (August 2013), 37-41.

Wu, L.-Z., Yim, F. H., Kwan, H. K., \& Zhang, X. (2011). Coping with Workplace Ostracism: The Roles of Ingratiation and Political Skill in Employee Psychological Distress. Journal of Management Studies, 49(1), 178-199.

Wu, W., Qu, Y., Zhang, Y., Hao, S., Tang, F., Zhao, N., \& Si, H. (2018). Needs frustration makes me silent: Workplace ostracism and newcomers' voice behavior 败. Journal of Management and Organization, 1-18

Warburton, D. E., Nicol, C. W., \& Bredin, S. S. (2006). Health benefits of physical activity: the evidence. Cmaj, 174(6), 801-809.

Williams, K. D., Bernieri, F. J., Faulkner, S. L., Gada-Jain, N., \& Grahe, J. E. (2000). The Scarlet Letter Study: Five Days of Social Ostracism. Journal of Personal and Interpersonal Loss, 5(1), 19-63.

Xu, E., Huang, X., \& Robinson, S. L. (2017). When Self-View Is at Stake: Responses to Ostracism Through the Lens of Self-Verification Theory. Journal of Management, 43(7), 2281-2302.

Xi, B., Liang, Y., He, T., Reilly, K. H., Hu, Y., Wang, Q., ... \& Mi, J. (2012). Secular trends in the prevalence of general and abdominal obesity among Chinese adults, 1993-2009. Obesity reviews, 13(3), 287-296.

Yan, Y., Zhou, E., Long, L., \& Ji, Y. (2014). The Influence of Workplace Ostracism on Counterproductive Work Behavior: The Mediating Effect of State Self-Control. Social Behavior and Personality: An International Journal, 42(6), 881-890.

Yang, J., \& Treadway, D. C. (2018). A Social Influence Interpretation of Workplace Ostracism and Counterproductive Work Behavior. Journal of Business Ethics, 148(4), 879-891.

Zippelius, R. (1986). Exclusion and shunning as legal and social sanctions. Ethology and Sociobiology, 7(3-4), 159-166. 
A. H. Samo - S. Khan - N. Ali - S. Ali 11/4 (2019) 3471-3484

Zhao, H., Peng, Z., \& Sheard, G. (2013). International Journal of Hospitality Management Workplace ostracism and hospitality employees ' counterproductive work behaviors: The joint moderating effects of proactive personality and political skill. International Journal of Hospitality Management, 33, 219-227.

Zarei Matin, H., Razavi, H. R., Azimy, L., \& Emamgholizadeh, S. (2014). Is stress management related to workforce productivity?. Iranian Journal of Management Studies, 7(1), 1-19. 